\title{
Estaciones de ski de la Región Metropolitana de Santiago: ¿nieve de clase mundial?
}

\section{Introducción}

$\mathrm{E}$ 1 siguiente artículo presenta los resultados de una investigación realizada durante el año 2004, que describe y analiza la evolución y proyección de los centros de turismo de invierno de la Región Metropolitana (RM) de Santiago, en términos de sus estrategias de desarrollo.

A partir de una revisión del estado de la industria de turismo de invierno a nivel mundial, se indagó acerca de las estrategias de desarrollo de las estaciones del Centro Cordillera de Lo Barnechea, en el contexto de los cambios que plantea la globalización y el nuevo posicionamiento de Santiago en el escenario de una economía articulada en torno a una red de ciudades globales. A través de entrevistas con algunos de los actores relevantes, tanto en el ámbito privado como el público, se observó si estas estrategias constituyen un proyecto integrado en torno al desarrollo del turismo de montaña en la RM, o si más bien se perfilan como un conjunto de proyectos diseminados sin una clara articulación.

Se analizó si el estado actual de los centros de ski se corresponde con estándares de nivel internacional, desde el punto de vista de una correcta identificación y aprovechamiento de las ventajas competitivas que presenta el Centro Cordillera como destino turístico. A su vez, se exploran las posibilidades de integración y complementariedad con otros destinos turísticos de la Región Metropolitana, en especial con el turismo ecológico de la zona cordillerana.

Socióloga, Pontificia Universidad Católica de Chile. E-mail: diezauberberg@yahoo.com

Sociólogo, Pontificia Universidad Católica de Chile. E-mail: alberto_stern@yahoo.ca
Esta investigación se sitúa en el marco del proyecto "Santiago: ciudad de clase mundial" desarrollado por el Instituto de Estudios Urbanos y Territoriales (IEU+T) de la P. Universidad Católica de Chile, al cual se ofreció esta investigación como un complemento a la elaboración de las Estrategias de Desarrollo para la Región Metropolitana. La investigación contó además con el financiamiento de SERNATUR, a través del Programa "Transferencia y colaboración entre universidades y Gobierno Regional Metropolitano de Santiago".

\section{Turismo global y turismo de invierno}

\subsection{Las ciudades en una economía global: las ventajas competitivas}

La perspectiva para discutir acerca del desarrollo de nuestras ciudades ha cambiado radicalmente en los últimos 30 años. Hemos evolucionado desde un modelo de desarrollo hacia adentro a una ciudad que se abre a la industria global y se caracteriza por ser "suburbanizada, policéntrica, de límites imprecisos, configurada como archipiélago, cuya dinámica expansiva ha ido incorporando a centros urbanos aledaños y áreas rurales, que han pasado a formar parte de un extenso periurbano" (De Mattos, 1999, p. 30). Además, hemos presenciado la irrupción de los denominados artefactos urbanos (De Mattos, 1999), tales como los malls, barrios cerrados, centros empresariales, theme parks, etc. Con ello ha cambiado no sólo el rostro de nuestras ciudades, sino también su orientación hacia una nueva estructura que busca competir en un circuito global de ciudades.

En este contexto, se genera la inquietud de replantear las estrategias de desarrollo de Santiago en concordancia con estándares internacionales, los cuales han sido elaborados a través de índices como el 
Ranking de Competitividad de Naciones elaborado por el World Economic Forum (WEF). En ellos Chile muestra logros ya asentados, como instituciones públicas respetables, un bajo nivel de corrupción y una fuerte estabilidad macroeconómica. Sin embargo, resta aún impulsar el desarrollo de otros indicadores, tales como capacidad de innovación, adopción de tecnologías y nivel de valor agregado de los productos de exportación. Estos resultan vitales para situar a Santiago dentro de un nivel de competencia deseable.

Como una forma de poner el acento en el desarrollo de ciertos atributos para una competencia a nivel global con estándares de calidad cada vez mayores, nace el concepto de ventaja competitiva introducido por Michael Porter (1998). El antiguo concepto de ventaja comparativa, que ponía énfasis en identificar las actividades más propicias a partir de las riquezas naturales de un país y el costo de producirlas respecto de otras regiones, es sustituido por la idea de liderar un mercado a través del desarrollo de ventajas como una serie de atributos que sitúan a la empresa en una posición privilegiada para ofrecer un producto con independencia de los costos de producción. Son factores externos a las determinantes microeconómicas, y que sin embargo pueden producir una enorme diferencia para situar un producto en el mercado.

Si trasladamos este concepto a las estrategias de desarrollo urbano, veremos que se pueden determinar ciertos factores clave para mejorar el posicionamiento de una región al interior de una red global de ciudades, haciéndola un lugar atractivo como sede de empresas transnacionales que inviertan y estimulen su desarrollo. Entre estos factores destacan la importancia de la estructura económica, los atributos territoriales, los recursos humanos y el medio institucional. En el caso de Santiago, dado un escenario macroeconómico favorable, se vuelve de vital importancia el impulso de un medio institucional que sepa reconocer $y$ potenciar las ventajas competitivas a través de políticas públicas o de cooperación público-privada que faciliten su desarrollo, y a la vez aseguren que sus beneficios se traduzcan en una mejora de las condiciones económicas para la totalidad de la sociedad, paliando los efectos de segregación socio-espacial característicos de las ciudades globales.
La ciudad de Santiago ha sido convocada a potenciar las claves que determinan su competitividad al interior de un circuito de ciudades globales. La Estrategia de Desarrollo Regional desarrollada por el IEU+T ha logrado identificar como una prioridad la tarea de potenciar el atractivo que la ciudad representa para los viajeros globales: turistas en busca de un destino para hacer negocios, realizar convenciones o simplemente disfrutar de las alternativas de esparcimiento que ofrece la ciudad. Desde este punto de vista, nuestra ciudad tiene un alto potencial como cluster de negocios, destacando entre sus virtudes la capacidad de ofrecer un interesante pool de alternativas de esparcimiento a sus visitantes (De Mattos, Fuentes y Sierralta, 2004).

Desde Santiago se puede acceder con facilidad a entornos naturales privilegiados, entre los cuales destacan las imponentes montañas de los Andes Centrales. Allí se sitúa una de las áreas esquiables más importantes del Cono Sur, el Centro Cordillera, conformado por las estaciones de El Colorado, La Parva, Valle Nevado y la Villa Farellones. Este complejo puede llegar a ser un eje estratégico decisivo para situar a Santiago como un destino preferido por viajeros de todo el orbe, y ofrece un enorme potencial como el escenario de un conjunto de experiencias de turismo de montaña, tanto para los santiaguinos como para sus visitantes.

Desde esta perspectiva, cabe preguntarse de qué manera los actores del sector privado y público se plantean el desafío de desarrollar las estaciones de ski del Centro Cordillera en términos de una oferta que combine infraestructura, calidad de servicios y capacidad de innovación. A su vez, resulta relevante observar la manera en que este artefacto urbano puede, al mismo tiempo, constituirse como un espacio propio de esparcimiento y creación de una cultura de montaña para los santiaguinos. En definitiva, resulta fundamental indagar cómo se está aprovechando un lugar que es único en el mundo, al conectar la naturaleza virgen de los Andes Centrales con una gran metrópolis.

\subsection{Industria del ski}

El ski fue durante siglos un medio de transporte utilizado en las zonas nevadas de Escandinavia. Su práctica como deporte se comienza a popularizar en los Alpes a comienzos del siglo XX, expandiéndose 
Rebeca Errázuriz y Alberto Stern

rápidamente en las montañas de Estados Unidos, Japón y también en los Andes. El desarrollo del ski como deporte ocurrió en el contexto de pequeños poblados agrícolas, balnearios termales y sanatorios de tuberculosos.

Los primeros grandes proyectos tuvieron un carácter más o menos planificado, pero en muchos casos estaban impulsados por el liderazgo de figuras carismáticas que representaban distintas formas de habitar la montaña modernamente, proponiendo una fusión con las construcciones y la cultura local (como ocurrió en Austria y Suiza), incorporando las tendencias modernistas y un estilo urbano en estaciones de altura (Francia) o imbuidos del espíritu pionero de la colonización del oeste (Estados Unidos). Durante las décadas de 1960 y 1970 esta industria vivió un crecimiento explosivo y se consolidó en los años ochenta. A mediados de esa década comienza a disminuir el número de estaciones debido a una competencia creciente. El período que le sigue está caracterizado por una disminución del público esquiador, la cual es compensada por la llegada de snowbordistas.

Esta industria ha experimentado los cambios organizacionales propios de la transición a la globalización. Destaca la tendencia hacia la interconexión de las estaciones a través de modalidades de integración organizacional verticales -como las mergers and acquisitions- $\mathrm{y}$ horizontales - como las joint ventures-, donde distintas empresas unifican parte de su operación manteniendo su autonomía. En Estados Unidos, las estaciones han ido adquiriendo un perfil corporativo a través de una lógica de expansión, comprando otros centros -ya sea de sectores vecinos o de zonas apartadas.

Las recientes transformaciones han afectado no sólo a la organización de las estaciones de ski, sino también el modo de concebir la cultura de montaña y los deportes de invierno. La concepción postfordista realza la montaña como un espacio de juego y libre circulación donde la estación plantea una puesta en escena en la que el visitante es el actor que crea su propia "experiencia” de montaña. Así, se abandona la lógica de la estación de ski concebida como espectáculo, donde el visitante asumía un rol más cercano al espectador. La estación deja de lado sus límites acotados y rígidamente definidos, propios de la lógica del enclave (Judd, 2003), y se abre a la posibilidad de habitar espacios híbridos, donde una visión tradicional de la montaña dialoga con el imaginario de la ciudad, la playa y la realidad virtual del videojuego.

\subsection{Estaciones de ski de Santiago}

El ski ha estado presente como un deporte practicado por los santiaguinos desde principios del siglo veinte. Los primeros aventureros intentaban deslizarse con sus precarios equipos por laderas del Cajón del Maipo o la mina La Escondida. Con el correr de los años, la zona de Farellones se fue estableciendo como el lugar favorito de los entusiastas del ski. Se habilitó un camino para llegar a la zona y se construyeron los primeros refugios, que hoy en día conforman lo que se conoce como la Villa de Farellones. Esta zona fue, junto con Portillo, la principal área esquiable del país.

Más tarde se habilitó el cerro Colorado, sobre cuya base también se construyeron casas de piedra y algunos edificios. A comienzos de los años cincuenta comenzó la formación de La Parva. Tras un breve período de habilitación por parte de unos pocos pioneros, el área fue adquirida por la familia Purcell, dueños también de Portilllo, quienes administraron el centro en los años siguientes hasta ser comprada en los '90 por Vial, Matte y Larraín. Mientras El Colorado se caracterizó por un desarrollo inmobiliario relativamente espontáneo llevado a cabo por Andacor S.A., La Parva fue concebida desde un principio como un negocio integrado, donde una misma empresa ofrecía un dominio esquiable de buen nivel y una oferta inmobiliaria de terrenos, en los que se instalaron refugios particulares y edificios de departamentos construidos por la misma empresa y otros constructores.

Hacia mediados de los ochenta, esta zona vivió una de sus ampliaciones más decisivas con la construcción de Valle Nevado. Este proyecto fue concebido como una estación integrada, al estilo de las estaciones de altura francesas. El centro fue construido por un equipo mixto de arquitectos chilenos y franceses y financiado por capitales corporativos de Francia y la cooperación del Estado chileno, el cual aportó con el financiamiento de un camino. El plan original para Valle Nevado no fue concretado 
en su totalidad debido al abandono del proyecto por parte de sus inversionistas principales. Actualmente, el centro ha sido adquirido por capitales chilenos, entre los cuales se encuentran los dueños de SENCORP. Valle Nevado representa la mayor interrogante desde el punto de vista de su futuro desarrollo, especialmente teniendo en cuenta las enormes posibilidades aún no explotadas que se contemplaron en su ambicioso plan original.

Haciendo una retrospectiva de la historia y desarrollo de los tres centros, es posible observar que si en un principio la industria del ski presentó un despliegue espontáneo y de pequeña escala, que no respondía a un plan a largo plazo, esta situación fue cambiando a medida que aparecían los nuevos centros de La Parva y en especial Valle Nevado. Este último no sólo constituyó la visión de un centro de ski concebido como "estación integral", sino que además implicó un involucramiento fuerte de capitales extranjeros y de aportes estatales, conformando una cooperación público-privada que impulsó de manera decisiva la industria del turismo de invierno en Santiago.

En ese sentido, cabe preguntarse cuál será el paso a seguir. La industria internacional del ski ha presentado una fuerte tendencia a la integración de distintas empresas en conglomerados, con estándares de calidad crecientemente competitivos. Esta presión debiese tener algún efecto sobre la forma en que se articulan las estaciones para conformar una oferta conjunta y coordinada entre ellos con otros centros del país, aerolíneas, agencias de turismo y agencias gubernamentales de fomento. Ésta últimas podrían asociarse en una alianza estratégica que vele no sólo por el mejoramiento de la calidad del producto, sino también por la elaboración de una estrategia conjunta con una proyección a largo plazo, que asocie a los centros con una visión integral de Santiago como destino turístico y centro de negocios.

\subsection{El estado actual de las estrategias de los "Tres Valles"}

Los tres centros visualizan su futuro a partir de un conjunto de situaciones comunes. Las irregulares temporadas de los últimos años han colocado en la agenda el tema de la nieve artificial como un factor esencial para poder comenzar cualquier desarrollo a futuro. Valle Nevado y El Colorado ya cuentan con sistemas desde el año 1998, mientras en La Parva recién fueron implementados en 2005 . Así, se siguen las tendencias de la industria del ski, que registra una cobertura cada vez mayor de nieve fabricada. La presencia de nieve en las pistas es un factor esencial para valorizar las inversiones inmobiliarias y hoteleras como el principal foco de crecimiento, siendo más relevante que la venta de tickets en términos de rentabilidad y volumen de negocios. De hecho, en Europa y Estados Unidos los principales centros han experimentado un crecimiento importante gracias al desarrollo inmobiliario, pese a que el número de esquiadores ha disminuido o se ha estancado (Clifford, 2003).

Respecto al panorama urbano de nuestras estaciones, El Colorado presenta un desarrollo inmobiliario incipiente. La zona de pie de pistas cuenta con el espacio y equipamiento adecuado para recibir esquiadores por el día, pero la zona destinada al desarrollo urbano está fuertemente desaprovechada. Su crecimiento a futuro no está claramente estructurado en un plan maestro, pero incluye la instalación de nuevos andariveles y la construcción de departamentos. En contraste, La Parva ha sido densamente construida, concentrando unas 6.500 camas, pero no cuenta con el equipamiento urbano necesario. Esto se debe principalmente a una escasa planificación urbana de largo plazo por parte de la estación, lo que no concuerda con el perfil de público de elite que el centro pretende mantener. Presenta problemas de estacionamiento, congestión, dificultades sanitarias y falta de espacios públicos, en especial durante la temporada alta. Junto con llevar a cabo un plan de reordenamiento urbano ha retomado su crecimiento, comenzando a entregar el proyecto $\mathrm{La}$ Parva Baja, lo que se traduce en una inversión de 4,5 millones de dólares.

Por su parte, Valle Nevado está conformado por un conjunto de hoteles, departamentos y unidades de alojamiento de personal organizados según el patrón de las "estaciones de altura" francesas. Alberga unas 2.000 camas en una amplia plataforma, donde también recibe esquiadores por el día. $\mathrm{Su}$ desarrollo se proyecta a partir de un nuevo master plan, encargado a la empresa canadiense Ecosign. Éste ha sido entregado pero aún no se anuncia públicamente el comienzo de su millonaria ejecución, la cual podría incluir la presencia de capitales extran- 
jeros. La propuesta entregada por Ecosign busca equilibrar de manera armónica el desarrollo inmobiliario con el crecimiento del dominio esquiable, redefiniendo su oferta para sumar al actual público internacional un sector más amplio de santiaguinos en una serie de etapas, que podrían concretarse en un plazo de 20 años, llegando a albergar unas 10.000 camas. Se pretende invertir en una infraestructura que permita ofrecer una experiencia de calidad para el esquiador por el día y para el turista internacional.

Los tres centros llevan a cabo una importante labor de promoción a nivel nacional y son escenario de actividades de los más variados productos e instituciones. Destaca que cada una de las estaciones se ha preocupado de realizar promociones en asociación con bancos que representen el perfil de sus clientes. El Colorado y Valle Nevado ofrecen también descuentos para estudiantes escolares y universitarios. De esta manera, se apuesta a la conformación de un grupo de esquiadores fanáticos, que en un futuro podrían estar dispuestos a invertir en una segunda o tercera vivienda en la montaña, abriendo este mercado a nuevos segmentos de creciente poder adquisitivo. Cabe destacar el perfil que quiere darse a las pistas bajas de El Colorado, situadas en Farellones, como un lugar de ski para principiantes, ofreciendo una tarifa más baja y de horario más flexible. Por su parte, Valle Nevado intenta diversificar sus actividades para que toda la familia pueda disfrutar de la montaña, incluidos los no esquiadores.

En el contexto de nuevas estrategias y promoción, las iniciativas para lograr una ocupación durante el verano con actividades alternativas al ski no son todavía un tema en la agenda, aún concentradas en optimizar sus actividades invernales. La habilitación del dominio esquiable para la práctica de mountain bike ha sido la respuesta más exitosa en Norteamérica y Europa para mantener las villas de montaña activas en verano. Esta modalidad presenta importantes similitudes con las actividades de invierno, tanto en las instalaciones como el producto que se ofrece y el tipo de público. Si bien se ha implementado esta forma de ocupación durante algunos veranos en Valle Nevado y El Colorado, estas incursiones no han sido acompañadas de una promoción que la haga atractiva, por lo que han sido abandonadas después de un escaso éxito. Las estaciones, además, son puntos de acceso ideales para las prácticas de montañismo que se realizan en la zona. Los centros no han logrado traducir el potencial que representan estas actividades, que generan una especial identidad de los usuarios con la montaña. Junto con las actividades deportivas, cabe destacar el potencial de las instalaciones de Valle Nevado como centro de eventos y convenciones. En años anteriores este lugar fue sede de numerosos congresos y seminarios, pero la actual administración ha optado por cerrar las instalaciones y concentrarse en las actividades de invierno.

A partir de lo expuesto, podemos ver que los centros están concentrados en consolidar su oferta individual, encontrándose aún en una etapa previa a la realización de una estrategia conjunta. Las diferentes modalidades de integración suelen producirse entre estaciones que una vez "desarrolladas" buscan la interconexión para ampliar su competitividad y atractivo. Actualmente se ofrecen tickets "Tres Valles" por el día y de temporada, pero sus precios son demasiado altos como para constituir una oferta atractiva, no existiendo mayores incentivos para el uso integrado de las pistas. No se trabaja actualmente en la promoción conjunta del área esquiable en su totalidad a través de un logo, un mapa de pistas integrado, una señalética común, etc. La posibilidad de avanzar en esta dirección es difícil, pues no existen posiciones completamente definidas en las tres empresas. Valle Nevado aparece como el más interesado en integrar las pistas, como una manera de facilitar el acceso a la totalidad del dominio esquiable a los visitantes extranjeros que buscan abarcar la mayor cantidad de pistas desde un mismo punto de partida. La Parva se muestra contraria, dado que se atentaría en contra de la idea de exclusividad que ellos ofrecen a sus clientes, en especial debido a que una conurbación del dominio esquiable significaría compartir las pistas con los esquiadores por el día del El Colorado. Esta última estación se manifestó abierta a la posibilidad de integración, pero no tienen una línea de acción concreta al respecto. Aunque existe un interés general por un área de ski integrada, se manifiesta además la necesidad de contar con la presencia de una autoridad neutral que medie, fomente o lidere dicho proceso.

En definitiva, el desarrollo inmobiliario y la nieve artificial constituyen los principales ejes de la hoja de ruta a seguir por los centros, lo que los sitúa en un 
estadio aún precoz en relación a otros polos de la industria del ski de nivel internacional.

\section{El turismo de invierno en la agenda pública}

Históricamente, Chile se ha caracterizado por tener una promoción turística discreta. La inversión en turismo es muy inferior a la que realizan países vecinos, bordeando los 4 millones de dólares. Si bien nuestro país ha mejorado su imagen en el exterior, esto no se debe a una campaña de marca específicamente turística. Los ejemplos exitosos a nivel mundial han llevado a plantear un progresivo aumento de la inversión en promoción, reconociendo cada vez más la importancia de promover a Chile como destino turístico en el extranjero.

El organismo asociado a esta tarea, el Servicio Nacional de Turismo (Sernatur), ha delegado los esfuerzos de promoción internacional a la Corporación de Promoción Turística de Chile (CPT), constituida en conjunto con las principales empresas que actualmente acogen a turistas internacionales, como el sector hotelero, las agencias de viajes, aerolíneas y empresas de turismo aventura. Esta instancia opera desde el año 2002 en un modelo que combina los aportes públicos con el financiamiento de sus socios privados, integrando distintos esfuerzos independientes de promoción internacional hacia una gestión conjunta. Este modelo de cooperación público-privada permite aumentar el impacto de cada una de las acciones de sus socios y coordinar las estrategias de promoción en torno a una imagen de Chile como marca. De hecho, uno de sus primeras estrategias fue definir la identidad turística de Chile, destacando sus atributos como un país seguro, con calidad de servicios y una variedad de paisajes de "naturaleza prístina”, que posteriormente dio paso a intentar posicionarnos como un "destino único" en el Cono Sur.

Dentro de la CPT se ha creado la marca $S k i$ Chile, fruto de la asociación de Portillo, Termas de Chillán y Valle Nevado, tres centros que junto a Lan y la CPT coordinan una serie de acciones destinadas a promover a Chile como país de nieve. Es financiada en un $70 \%$ por las empresas y en un $30 \%$ por Sernatur. Su primer objetivo ha sido lograr que el público internacional relacione a nuestro país con la nieve, así como elaborar una oferta unificada que destaque los principales atributos del ski en Chile.

Este parece ser uno de los primeros proyectos de cooperación público-privada que involucran al Estado en la promoción de nuestras estaciones. Ski Chile se ha ocupado de esta actividad reuniendo su estrategia de marketing en los mercados de Brasil, Estados Unidos, México y Colombia, concentrando en ese orden los recursos asignados a la promoción. Sin embargo, son sólo tres las estaciones que participan y se benefician de estas actividades: Portillo, Termas de Chillán y Valle Nevado, el único centro de ski de la Región Metropolitana miembro de Ski Chile. Las demás estaciones chilenas no han sido incorporadas, ya que no cuentan con el tipo de oferta hotelera de alto nivel que esta marca promociona como conjunto. Dado que Valle Nevado utiliza el "gancho" de los "Tres Valles" para hacer su promoción internacional, sería razonable integrar a mediano plazo a los otros dos centros. Por el momento, El Colorado y La Parva pueden aparecer como beneficiarios indirectos de Ski Chile (free riders), pudiendo dar a conocer su dominio esquiable a través de Valle Nevado. No obstante, debemos advertir que la marca Ski Chile tiene la particularidad de centrarse en la oferta hotelera, y no incluye otras posibilidades como el arriendo de refugios y departamentos existentes en Farellones o La Parva; en cambio, a nivel internacional, la promoción del turismo de invierno suele estar estrechamente relacionada con las centrales de arriendo.

Pero más allá de la discusión sobre el beneficio o perjuicio que significa estar excluidos de Ski Chile, queda claro que aún no se ha hecho el esfuerzo (público o privado) de identificar a las estaciones del Centro Cordillera como un atractivo perteneciente a la ciudad de Santiago y que, por lo tanto, conlleve acciones de promoción, impulso e incentivo acordes a una estrategia de desarrollo y posicionamiento de nuestra ciudad, la cual compete en gran parte a la agenda pública. Todo indica que poco a poco los organismos estatales han ido incorporando al turismo como un factor de desarrollo para el país, dirigiendo importantes esfuerzos para generar alianzas con las empresas que se dedican a este rubro. Sin embargo, en el caso específico del turismo de ski, existen aún una serie de prejuicios que dificultan a los entes públicos visualizar la oportunidad que representa la nieve como recurso. 
Existió un acuerdo generalizado entre los "Tres Valles" al señalar que el Estado aún considera al ski como una actividad exclusiva para las elites, sin reconocerlos como un foco de desarrollo importante para la industria del turismo nacional, capaz de abrir puestos de trabajo y generar divisas para el país. Todos coincidieron en que los centros de ski son un negocio extremadamente riesgoso, al estar sujeto a los caprichos de la naturaleza y a las crisis económicas y de seguridad en el escenario internacional. Estos empresarios afirman que son ellos los únicos que han contribuido en el surgimiento de esta industria, asumiendo todos los riesgos e inversiones, siendo que en otros países esta actividad cuenta con importantes subvenciones y descuentos tributarios.

Este sentir no parece ser antojadizo al observar, por ejemplo, el nacimiento de estaciones como Courchevel en Francia, donde a mediados de los años cincuenta se decidió invertir parte del presupuesto municipal de transporte público en andariveles. Con esto no sólo se dio a las pistas de ski el status de espacio público y futura fuente de desarrollo para la región alpina, sino que además se inauguraba el florecimiento de esta industria de la mano del Estado, que le brindó una importancia fundamental como actividad económica y cultural. Para los franceses los deportes de nieve forman una parte importante de la cultura nacional, y existe la voluntad de generar una apropiación de la montaña -una "cultura alpina"-, cuyo imaginario involucra elementos de tradición y progreso. La conquista de la montaña ha tenido una lectura democrática, donde el ski es una actividad nacional que se incorpora incluso en la formación escolar.

En el caso chileno, desde el punto de vista cultural ha habido una escasa apropiación de la montaña, en especial entre los santiaguinos. La cordillera aparece en nuestro imaginario a una distancia muchísimo mayor de la real, en especial entre los sectores sociales menos favorecidos. La conquista de la montaña entre los santiaguinos fue una empresa de la elite, y hasta ahora no se han hecho suficientes esfuerzos tendientes a democratizar este espacio. La baja prioridad con que aparece la construcción de un nuevo camino a Farellones en la agenda pública, tiene asociado el prejuicio de que se estaría construyendo el camino para un lugar de vacaciones de la elite. Esta visión resulta equivocada si se tiene en cuenta la creciente masificación del ski y la montaña como actividad de recreación, lo cual tiene un correlato en las estrategias de El Colorado y Valle Nevado, que actualmente concentran sus esfuerzos en captar el nuevo abanico de clientes que se abre para esta industria.

La importancia que ha cobrado la montaña como atributo fundamental de la ciudad de Santiago, tanto para sus residentes como para sus visitantes, ha sido reconocida por el ex-presidente Ricardo Lagos a través de la iniciativa "Sendero de Chile", y por distintos organismos ecológicos que han rescatado el valor de la montaña como parte de nuestro patrimonio natural y cultural. Si bien muchas de estas organizaciones han asumido una actitud de hostilidad hacia el desarrollo de actividades al interior de la zona cordillerana, muchas otras han tenido un rol gestor en materia de actividades turísticas.

Las estaciones de ski del Centro Cordillera se encuentran íntimamente relacionadas con el turismo ecológico, pues están instaladas al interior del Santuario de la Naturaleza Yerba Loca. Esto significa también que todo desarrollo deberá contar con un estudio de impacto ambiental e incorporar criterios de sustentabilidad para no comprometer el patrimonio natural. Algunos organismos ecológicos han dado una voz de alerta, iniciando gestiones legales para frenar el crecimiento urbano de la zona. Estas iniciativas conservacionistas no han logrado dar una propuesta que resuelva dicha convivencia en un modelo de complementariedad. Conflictos de esta índole no son nuevos en la industria global del ski, sobre todo en los lugares donde las pistas se abren paso a través de la tala de bosques silvestres. Sin embargo, en Europa y Norteamérica, los organismos a cargo de los parques nacionales y los centros de ski han logrado trabajar juntos y aunar sus objetivos, promoviendo el desarrollo de un turismo sustentable para el medio ambiente, enfrentando la sana crítica y fiscalización por parte de distintas ONG que ejercen un mecanismo de control y motivan políticas de accountability y transparencia.

En nuestro caso, creemos que existe la posibilidad de generar una alianza entre el turismo ecológico y el turismo de nieve. La voluntad actual de algunos organismos públicos y privados por activar circuitos ecológicos en la precordillera y las altas cum- 
bres, debiese incorporar a las estaciones de ski como zonas habilitadas para disfrutar de los atractivos de la montaña. La labor de "Protege", asociación de municipalidades de la zona oriente de Santiago, dedicada a recuperar nuestros espacios cordilleranos, resulta especialmente interesante como una oportunidad para integrar a los centros de ski en circuitos de turismo ecológico. Ellos se han dedicado a recuperar y conservar este espacio andino para los ciudadanos, mencionando entre sus objetivos: "La colonización cultural de los Andes, el desarrollo urbano en armonía con las montañas y la importancia económica de conservar la montaña como escuela para la formación de valores". La habilitación de senderos en las zonas del Cajón del Maipo y Lo Barnechea podrían perfectamente integrar a las estaciones de ski como punto de inicio, llegada o de paso al interior de una red más amplia de atractivos naturales.

La posibilidad de conformar un complejo turístico de gran envergadura, que genere una alianza entre los centros de ski y los parques ecológicos que lo circundan, no sólo podría constituir una estrategia exitosa de apropiación democrática de la montaña, sino que además concuerda con el perfil turístico que la CPT intenta darle a Chile, como un país de naturaleza prístina que ofrece además la ventaja de poseer servicios de clase mundial. En términos de turismo internacional, tanto los parques como las estaciones serían capaces de ampliar su espectro de visitantes, generando un atractivo rentable en el cual bien valdría la pena invertir, y que podría ofrecer una variedad de actividades a pocos kilómetros de una gran ciudad, integrando el ski a la naturaleza como un "gancho" que motive al visitante a conocer nuestros destinos ecológicos. Un proyecto de esta índole exige la creación de un modelo de cooperación público-privada capaz de aunar voluntades para facilitar la superación de trabas y dificultades que puedan entorpecer las distintas opciones de desarrollo sustentable para la cordillera. Al mismo tiempo, requeriría trabajar en la elaboración de un marco organizacional y normativo para el fomento, regulación y gestión de estaciones de ski, que motive el desarrollo de ventajas competitivas para el turismo de montaña.

El Plan Regulador en vías de aprobación que ha elaborado la Municipalidad de Lo Barnechea para el Centro Cordillera, puede traducirse en un aporte fundamental en la regulación y planificación urbana de las estaciones. Pero este marco legal no constituye en sí mismo una herramienta capaz de proponer una gestión conjunta con los “Tres Valles” para la promoción de un circuito turístico al interior de la comuna. El Centro Cordillera podría investigar la realización de un estatuto que incorpore facilidades y fomentos especiales para los empresarios, generando una alianza entre éstos y la municipalidad en torno a una línea estratégica común que identifique las particularidades que posee el desarrollo de centros invernales. Este tipo de alianzas tiene antecedentes en la industria del ski, como demuestra el esfuerzo realizado en la provincia canadiense de British Columbia en base al modelo de gestión del municipio de Whistler, donde se creó un gobierno local especialmente diseñado para enfrentar las especificidades de la gestión de una estación de ski. El aprendizaje que produjo esta experiencia se recogió en una ley que facilita y regula el desarrollo de resorts de montaña, poniendo énfasis en la necesidad de establecer una alianza en torno a los esfuerzos de promoción.

La Mountain Resort Act (Ministry of Community, Aboriginal and Women's Services, 2001) establece la delimitación de zonas para la instalación de resorts, acogiéndose a un plan de beneficios y compromisos compartidos. La ventaja de este tipo de administración es que permite contar con herramientas efectivas para lidiar con las dificultades específicas que implican el desarrollo de centros de ski. La municipalidad, en conjunto con la Asociación de Resorts, vela por el cumplimiento de una serie de compromisos aplicables a cualquier inversionista y/o propietario que pase a ser miembro de la asociación, tales como el seguimiento de una línea arquitectónica y urbana coherente con el plan maestro de la estación, el pago de permisos de construcción más elevados que internalicen costos en que incurra la municipalidad para proveer servicios adicionales (no sólo para la habilitación de camino, alcantarillados y espacios públicos, sino también el alojamiento y servicios accesibles para el personal del centro), y la responsabilidad de hacerse cargo del impacto ambiental y las presiones económicas que el crecimiento urbano pueda ejercer sobre la comunidad. Estos compromisos llevan aparejados un conjunto de beneficios que hacen atractivo para el inversionista formar parte de esta asociación, como una 
mayor capacidad de endeudamiento por parte de la municipalidad para construir instalaciones en favor del desarrollo de la comunidad, el establecimiento de un gravamen destinado a la promoción y marketing de la zona, y en general, una serie de herramientas que disminuyen los riesgos de los inversionistas iniciales, quienes ingresan a una red de gestión conjunta para el desarrollo y promoción de la zona.

Aunque la aplicación de un modelo semejante presenta un perfil legal que difiere del sistema chileno, no deja de ser ejemplar como un caso que ilustra la importancia y necesidad de crear un marco institucional favorable, que a partir de la alianza de públicos y privados genere un pilar para la gestión y promoción turística de un área específica que a largo plazo, administrada correctamente, puede traer beneficios enormes a complejos turísticos de montaña. El primer paso hacia un modelo de estas características en el Centro Cordillera y las reservas ecológicas que lo circundan, sería algún tipo de integración o coordinación en la gestión de los Tres Valles, que permita facilitar una alianza con la municipalidad y otros organismos estatales. Resulta un gran desafío el transmitir esta visión a los directivos de las estaciones, quienes ven con recelo la posibilidad de estrechar sus relaciones con la competencia.

Una alianza así conseguiría producir además una fuerte sinergia con la ciudad de Santiago, la cual podría promocionarse a través de estos atractivos en un circuito de turismo urbano que incluya a los centros, al turismo ecológico y otros atractivos complementarios como la ruta del vino, en un mismo destino.

\section{El futuro de los "Tres Valles" y la cultura de montaña en Chile: algunas reflexiones finales}

En el caso de los centros de ski del Centro Cordillera, lo que a simple vista pudiera parecer un producto afianzado se encuentra en una fase temprana, si se tienen en cuenta factores como el creciente poder adquisitivo de la clase media, la emergencia de Santiago como ciudad para el turismo urbano y de negocios y el tremendo potencial de innovación que tiene esta industria; la cual se ha estado reinventando constantemente durante las últimas décadas, abriendo nuevos nichos de mercado.
A la luz de la industria global del ski se trata de un "diamante en bruto". Su zona geográfica es, en opinión de muchos entendidos, la que tiene mayor potencial de desarrollo para el turismo de invierno en el Cono Sur, y su topografía resulta especialmente favorable para habilitar una gran cantidad de canchas para esquiadores de nivel intermedio, característica tremendamente apetecida en el mercado internacional. A esto debe agregarse una excelente calidad de nieve, su ubicación estratégica a pocos kilómetros de una gran metrópolis y un aeropuerto internacional. Este enorme potencial cuenta aún con una infraestructura y servicios más bien reducidos en tamaño y calidad. La intención de los centros es crecer en esa dirección.

Los planes de crecimiento de Valle Nevado son sumamente ambiciosos y si llegan a concretarse, convertirían a este centro en un complejo turístico invernal de dimensiones sin precedentes en Chile. Sin embargo, estos planes aún se encuentran en el papel y es difícil saber qué camino tomarán los socios Senerman y Ergas en el futuro. Actualmente, Senerman parece más interesado en llevar a cabo sus planes para la Portada de Vitacura en la ciudad de Santiago. Todo dependerá de la prioridad que tengan los proyectos de Valle Nevado para estos grandes empresarios que, quizás por no tener demasiada experiencia ni conocimiento sobre el negocio de las estaciones de ski, parecen no vislumbrar la oportunidad que podría traer un desarrollo importante en esta materia.

En un escenario optimista, podríamos pensar que se impondrán las tendencias de la industria global del ski, generándose algún tipo de alianza en la gestión y promoción del Centro Cordillera, basada en la disponibilidad creciente de tecnologías de información y la posibilidad de llevar a cabo una administración conjunta más racional que la existente, sin que esto signifique necesariamente que se unifiquen bajo un mismo propietario. La reticencia de La Parva a integrarse para mantener su exclusividad podría tener buenas razones para ceder: su crecimiento inmobiliario presionará para facilitar el acceso a un gran dominio esquiable unificado. Para que esto ocurra, la visión de sus gerentes debe evolucionar desde una concepción del ski como actividad suntuaria a una visión sustentable a largo plazo en que prime la lógica del negocio rentable. 
Es importante destacar el deseo de las estaciones de que exista un ente público que pudiese actuar como mediador en las negociaciones de integración. La experiencia con el Plan Regulador como instancia de diálogo indica que la Municipalidad es una buena candidata, dado que además le interesa participar en la gestión de los centros. Esta integración podría traer consecuencias positivas para el complejo en su totalidad: la unificación de las pistas puede presionar a La Parva y El Colorado para que se desarrollen de una manera equilibrada y planificada, manteniendo sus ofertas inmobiliarias diferenciadas (exclusiva vs. accesible) y acordes a la ampliación de las pistas, las cuales se ofrecerían como un espacio lúdico y deportivo, dando la bienvenida a todos los que quieran disfrutar de la nieve y la montaña.

De hecho, esta proyección recoge algunas de las características del modelo de negocios que ha llevado a la empresa canadiense Intrawest, responsable de estaciones emblemáticas como Whistler, a ser uno de los líderes de la industria mundial. Intrawest se ha especializado en adquirir centros de ski con un dominio esquiable atractivo, que de manera similar al Centro Cordillera están por debajo de sus posibilidades de desarrollo tanto de ski como inmobiliario; pero que concentran un gran potencial en la medida en que se encuentran cercanas a núcleos urbanos con una importante población y facilidad de acceso. El caso de Intrawest se torna especialmente relevante si consideramos que los actuales consultores de Valle Nevado, Ecosign, han trabajado en forma estrecha con esta compañía, desarrollando planes maestros en muchas de sus adquisiciones.

El escenario general de desarrollo para los "Tres Valles", y su creciente importancia como un núcleo ubicado en las afueras de una metrópolis, exige que los centros tomen conciencia de los desafíos que significan situarse en la cordillera de Santiago. Sin negar la oportunidad de progreso que puede ofrecer la adopción de un modelo semejante al de Intrawest para Valle Nevado, es necesario tomar en cuenta que éste no se puede aplicar en desmedro de las características locales que hacen de nuestras montañas una experiencia única en comparación a otras estaciones del mundo. El paisaje andino, coronado por el cerro El Plomo, el Apu más austral del antiguo imperio inca, ofrece una fisonomía geográfica muy distinta a la de los Alpes o las Rocallosas. La construcción de una villa alpina que busque asemejarse lo más posible a un estereotipo producido en serie le restaría al Centro Cordillera parte importante de su encanto, de su valor local y de la especificidad de nuestra oferta para el turista global. Se debe intentar hacer de la experiencia de montaña andina un producto de exportación no tradicional, en lugar de buscar importar la experiencia ofrecida por otras estaciones bajo el modelo de la villa alpina tipo enclave (Judd, 2003), que se cierre a su conectividad con la ciudad y la experiencia del turismo urbano, en la que se valora la posibilidad de estar inmerso en una cultura distinta y acceder de manera espontánea a una trama de experiencias locales. La posibilidad de que el Centro Cordillera sea capaz de escapar de la lógica del enclave, para abrirse a un circuito amplio de turismo que explote su conectividad con la naturaleza de los alrededores y con la ciudad de Santiago, dependerá en gran medida de la capacidad de las entidades públicas y la comunidad organizada de asumir un rol activo en el futuro de los centros de ski como un capital económico y cultural de la ciudad, sometiendo a discusión sus estrategias de desarrollo.

La creciente importancia que puede llegar a tener el Centro Cordillera en materia de turismo internacional, no debiese ser desaprovechada por los agentes públicos interesados en promover a Santiago como destino turístico privilegiado. Las políticas turísticas actuales de la Intendencia han dado mucha importancia a la Ruta del Vino y al Cajón del Maipo, pero por alguna razón no han incluido aún a los centros de ski en el conjunto de atractivos a través de los cuales se busca posicionar a Santiago dentro del circuito de ciudades globales.

Creemos que esta tremenda oportunidad no debe ser desaprovechada, sobretodo teniendo en cuenta la posibilidad de conformar un complejo turístico capaz de conjugar las estaciones de ski con el turismo ecológico, satisfaciendo la necesidad de contar con espacios de esparcimiento y recreación para los santiaguinos, siendo al mismo tiempo un lugar en que se da la bienvenida al turista internacional. El Centro Cordillera está llamado a constituir un nodo de desarrollo y progreso para el turismo andino, que en alianza con otros destinos de la precordillera y el Cajón del Maipo, puede elevar el nivel de competitividad y atractivos de Santiago, aportar sus conocimientos en promoción interna- 
cional y traer nuevos visitantes que ejerzan presiones por un aumento de la calidad de los servicios turísticos y actividades de la zona en su conjunto, generando oportunidades de empleo y negocios para los lugareños y las PYMES de esta zona. Pero para ello resulta necesario que los organismos públicos comprendan la importancia de generar un marco favorable, que se ocupe de facilitar y regular al mismo tiempo el desarrollo de un complejo de esta magnitud.

Las políticas del Estado en torno al fomento de la industria del turismo no han tenido una orientación clara y una continuidad en el tiempo. En general, ha sido la iniciativa privada la que ha constituido el principal motor de la actividad turística. Las políticas se orientan actualmente a potenciar actividades y destinos turísticos novedosos y poco explotados a cargo de pequeñas y medianas empresas, dejando a las empresas de mayor envergadura sin un organismo público que se ocupe de sus actividades. Esto se traduce en una fuerte desconexión entre los esfuerzos públicos y privados en torno al turismo, desperdiciando la oportunidad de emprender alianzas estratégicas que permitan que las PYMES emergentes se beneficien con la experiencia de empresas de mayor trayectoria para constituir junto a ellas nodos de desarrollo para el turismo chileno, como podría ser el caso ya mencionado del Centro Cordillera, los Parques Nacionales y el Cajón del Maipo como un gran sistema de turismo cordillerano.

A su vez, es necesario que las políticas públicas recuperen el espacio de la montaña y la nieve como un lugar para todos los chilenos. Si el ski es concebido como una actividad de elite, la democratización de la nieve implica emprender políticas comunicacionales que redefinan un sentido de apropiación de la montaña en el imaginario cultural. Un esfuerzo encaminado en este sentido es el proyecto "Protege", que se ha propuesto acercar a los santiaguinos a su cordillera. Esta instancia podría aprovecharse para incluir al ski y al Centro Cordillera como una forma más de democratizar el espacio cordillerano, facilitando el ingreso de un público más amplio a nuestros valles andinos. El interés de la Municipalidad de Lo Barnechea por habilitar espacios públicos para la llegada de visitantes por el día al Centro Cordillera, se enmarca también en este esfuerzo, abriendo lugares que permitan hacer de las estaciones de ski un lugar para todos.
La inserción de los centros de ski a una Estrategia de Desarrollo Regional, como un atractivo fundamental de la ciudad de Santiago, es una buena oportunidad para promocionar el espacio cordillerano como uno de los rostros emblemáticos de Chile en el extranjero, produciendo al mismo tiempo una identificación de este espacio con el país que impulse a los ciudadanos a apropiarse de él. Nuestras estaciones de ski deben llegar a ser tan emblemáticas como lo han sido el vino, el cobre o el mar; símbolos de la imagen exitosa de Chile en el extranjero, en una síntesis simbólica que combine el referente nacional de nuestra geografía andina con una imagen de modernidad y desarrollo sustentable, susceptible de generar una mayor identificación y orgullo entre los chilenos.

Al contrario de lo que podría pensarse, la lógica de democratización de la nieve supone no sólo la transición de nuestro imaginario cultural hacia la concepción de la montaña como un lugar abierto, sino que significa también transformarla en una actividad económica rentable para la ciudad, dejando en el pasado su función de símbolo de prestigio para una elite que buscaba hacer del ski un objeto de gasto suntuario, que no estaba orientado fuertemente hacia la producción de utilidad. La alianza entre los organismos públicos y las estaciones de ski en torno a la promoción de nuestra nieve debe tener como orientación un criterio de interés público a partir del cual brindar una experiencia de montaña única, que se vuelva compatible con los intereses de Santiago como ciudad de turismo internacional, siendo capaz de atraer a sus visitantes por la manera en que es disfrutada y compartida por sus propios habitantes.

\section{Referencias bibliográficas}

Clifford, H. (2003). Downhillslide: Fueled by mergers and buyouts, America's corporate ski resorts are more about real estate than ski runs. http:// www.findarticles.com/p/articles/mi_m1525/ is_1_88/ai_98469849/pg_2

De Mattos, C. (1999). "Santiago de Chile, globalización y expansión metropolitana: lo que existía sigue existiendo". EURE Revista Latinoamericana de Estudios Urbano Regionales, 25, 76:

De Mattos, C., L. Fuentes y C. Sierralta (2004). Santiago, ¿ciudad de clase mundial? Factores en el 
posicionamiento internacional de Santiago. Santiago: EURE Libros.

Judd, D. (2003). "El turismo urbano y la geografía de la ciudad". EURE Revista Latinoamericana de Estudios Urbano Regionales, 29, 88:

Ministry of Community, Aboriginal and Women's Services (2001). A guide to British Columbia's
Mountain Resort Associations Act. http:// www.mcaws.gov.bc.ca/lgd/gov_structure/ index.htm

Porter, M. (1998). Competitive advantage: Creating and sustaining superior performance. New York: Free Press. 